\title{
Radiographic evaluation of third molar genesis in Greek orthodontic patients
}

This article was published in the following Dove Press journal:

International Journal of General Medicine

13 September 2013

Number of times this article has been viewed

\author{
Georgia Barka' \\ Konstantinos Marathiotis ${ }^{2}$ \\ Michael Protogerakis ${ }^{3}$ \\ Andreas Zafeiriadis ${ }^{4}$ \\ 'Department of Dentoalveolar \\ Surgery, Implant Surgery and \\ Radiology, School of Dentistry, \\ Aristotle University of Thessaloniki, \\ ${ }^{2}$ School of Biology, Faculty of \\ Science and School of Dentistry, \\ Aristotle University of Thessaloniki, \\ Thessaloniki, Greece; ${ }^{3}$ Clinical Implant \\ Dentistry, School of Dental Sciences, \\ Newcastle University, Newcastle \\ Upon Tyne, UK; ${ }^{4}$ Department of \\ Orthodontics, School of Dentistry, \\ Aristotle University of Thessaloniki, \\ Thessaloniki, Greece
}

Objectives: The study reported here investigated the first radiographic evidence of third molar (M3) formation, their incidence and distribution as well as their congenital absence on the right or the left side in either the maxilla or the mandible, in both male and female Greek orthodontic patients.

Materials and methods: A total of 618 panoramic radiographs were initially examined. After the application of inclusion/exclusion criteria, the group finally selected consisted of 428 patients (mean age 11.64 years, range $5-18$ ): 179 males (mean age $11.73 \pm 2.46$ ) and 249 females (mean age 11.57 \pm 2.45 ). The collected data were analyzed using SPSS software (IBM, Armonk, New York, NY, USA). The level of significance for all analyses was set to $p=0.05$. The chi-square $\left(\chi^{2}\right)$ test was used to assess the relationships between variables. The Wilcoxon's signed-rank test and the Mann-Whitney $U$ test were also used for comparisons as well as the Spearman's rho test for correlations.

Results: M3s were first detected in females at the age of 7 years whereas males followed one year later at the age of 8 years. A strong correlation between age and M3 development was revealed for both sexes (Spearman's rho $=0.177, p=0.05$ ). Presence of all four M3s was the most common incidence (present in $70.8 \%$ of study subjects), followed by the agenesis of two (12.1\%), agenesis of all four (8.4\%), one (6.8\%), and three (1.9\%) M3s. Congenitally missing $\mathrm{M} 3 \mathrm{~s}$ in all subjects showed a significantly greater predilection for the maxilla over the mandible (19.6\% and $15.5 \%$, respectively) (Wilcoxon signed-rank test $Z=-2.404, p=0.016$ ). However, the distribution was found equal between the two sides of the jaws. The difference between the absent frequencies of $\mathrm{M} 3 \mathrm{~s}$ in the mandible and the maxilla was found statistically significant for the total sample (McNemar's test, $p<0.001)$ and for males $(p=0.041)$ as well.

Conclusion: The study data may provide a reference for the M3 genesis in Greeks.

Keywords: dental genesis, maxilla, mandible

\section{Introduction}

The development of third molars (M3s), the calcification time, the position, and the direction of eruption, as well as their impaction or agenesis have long been a concern to the dental profession. ${ }^{1-3}$

A critical issue in the study of M3 development concerns the selection of criteria for the correct diagnosis of agenesis in unformed teeth, because M3s eventually become visible in an undetermined number of cases. Most published studies considering this question have attempted to establish the earliest age at which M3 development can be assessed using panoramic radiographs with the least possible uncertainty. For example, Gorgani et $\mathrm{al}^{4}$ reported that in a USA population $90 \%$ of $\mathrm{M} 3 \mathrm{~s}$ were visible by the age of 10 to 11 years, whereas Barnett ${ }^{5}$ reported a case in which radiological evidence of
Correspondence: Konstantinos Marathiotis Agias Theodoras II, Gr-54623,

Thessaloniki, Greece

$\mathrm{Tel}+302310999483$

$\mathrm{Fax}+302310999549$

Email kostas.marathiotis@gmail.com 
M3 formation was first apparent at age 15. With regard to the Japanese population, ${ }^{2}$ it was reported that the calcification of M3s begins at approximately 8 years, while, for the Spanish population, ${ }^{6}$ the onset of M3 formation ranged from 5.86 to 14.66 years. Richardson ${ }^{7}$ stated that the majority of M3s are radiographically apparent by the age of 11 to 12 years. Further, he found that when M3 genesis is delayed beyond the age of 10 years, the probability of four M3s developing is reduced by about 50 percent.

The published data seem to suggest that the time course of M3 mineralization is affected by the ethnic affiliation of each investigated population. However, so far, the influence of various geographic origins on tooth development has not been proven, with different authors reporting different results on formation frequency and the congenital absence of M3s in different ethnic groups., ${ }^{4,6,9}$ Therefore, in the present study we aimed to: detect the first radiographic evidence of tooth formation to determine the earliest age at which M3s develop in this specific population; investigate the number of M3s present per person at each age, for the total sample and according to sex; explore the role of both age and sex in M3 formation; and investigate the incidence of the congenital absence of these teeth on the right or left side in either the maxilla or the mandible, for both males and females, complementing a previous study conducted in Greeks. ${ }^{10}$

\section{Materials and methods}

The initial panoramic radiographs of orthodontic patients consecutively selected from the archives of the Postgraduate Orthodontic Clinic, School of Dentistry, Aristotle University of Thessaloniki, Greece were examined. The radiographs were part of the standard diagnostic records and were taken with the same equipment (Orthopantomograph 10E, Palomex Instrumentarium, Hyryla, Finland).

Initially, we examined the clinical records of 618 patients who had been referred to the clinic from 1995 to 2009 and either had finished or were still receiving orthodontic treatment. Patients who met the inclusion criteria had complete records (medical and dental history, study casts, as well as panoramic and lateral cephalometric radiographs taken before and after treatment). Exclusion criteria were any congenital anomalies and/or syndromes, abandoned or discontinued treatment plans, and/or poor quality panoramic radiographs. We set the lower limit for the age of our sample at 4 years and the upper limit at 18 years and sought to investigate M3 crypt formation from the early stages of life to adulthood.
Initial panoramic radiographs were examined to determine whether there was M3 formation or agenesis. The onset of M3 formation was diagnosed either by the presence of uncalcified crypt or by the mineralization of cusp tips. If neither of these stages of M3 formation were apparent, it was considered as a sign of agenesis. To avoid errors in the estimation of M3 agenesis in cases in which it was impossible to judge the presence or absence of M3 germs from panoramic radiographs taken at the initial examination, we used panoramic radiographs taken during or after the patient's orthodontic treatment. If no signs were observed in these radiographs, M3 agenesis was confirmed. At this point, we classified the teeth as developmentally missing when no evidence was found in the records that they had been extracted.

To check for diagnostic reproducibility, the radiographs of 35 randomly selected patients from the initial 428 were re-evaluated after an 8 -week interval by the same investigator. The McNemar statistical test ${ }^{11}$ showed no statistically significant differences.

The collected data were analyzed using the SPSS software (v 19.0; IBM, Armonk, New York, NY, USA). The level of significance for all analyses was set as $p=0.05$. The chi-square $\left(\chi^{2}\right)$ test was used to assess the relationships between variables. The Fisher's exact test was used in cases where the expected frequencies in each cell were $<5$, as this test allows the computation of the exact probability of the chi-square statistic in such cases. ${ }^{12}$

The Wilcoxon signed-rank test was used to compare the number of teeth on different sides, while the Mann-Whitney test was used to compare the number of third molars between sexes, and Spearman's rho test was used to investigate the correlation between age and M3 formation for both sexes.

\section{Results}

Figure 1 illustrates the age and sex distribution of the study population. Of the 428 patients (mean age 11.64 years, range 5-18), 179 were males (mean age $11.73 \pm 2.46$ ) and 249 were females (mean age $11.57 \pm 2.45$ ).

Table 1 presents the number of M3s that were radiographically evident at each age for both sexes and the total sample. In female panoramic radiographs, the age at which M3s were first detected was 7 years, whereas in males 8 years. No significant difference was found between the M3s 18 and 28, and 38 and 48 in males or females. Statistical analysis revealed a correlation between age and M3 development for males (Spearman's rho $=0.177$ ) at a significance level of 0.05 . The correlation between age and 


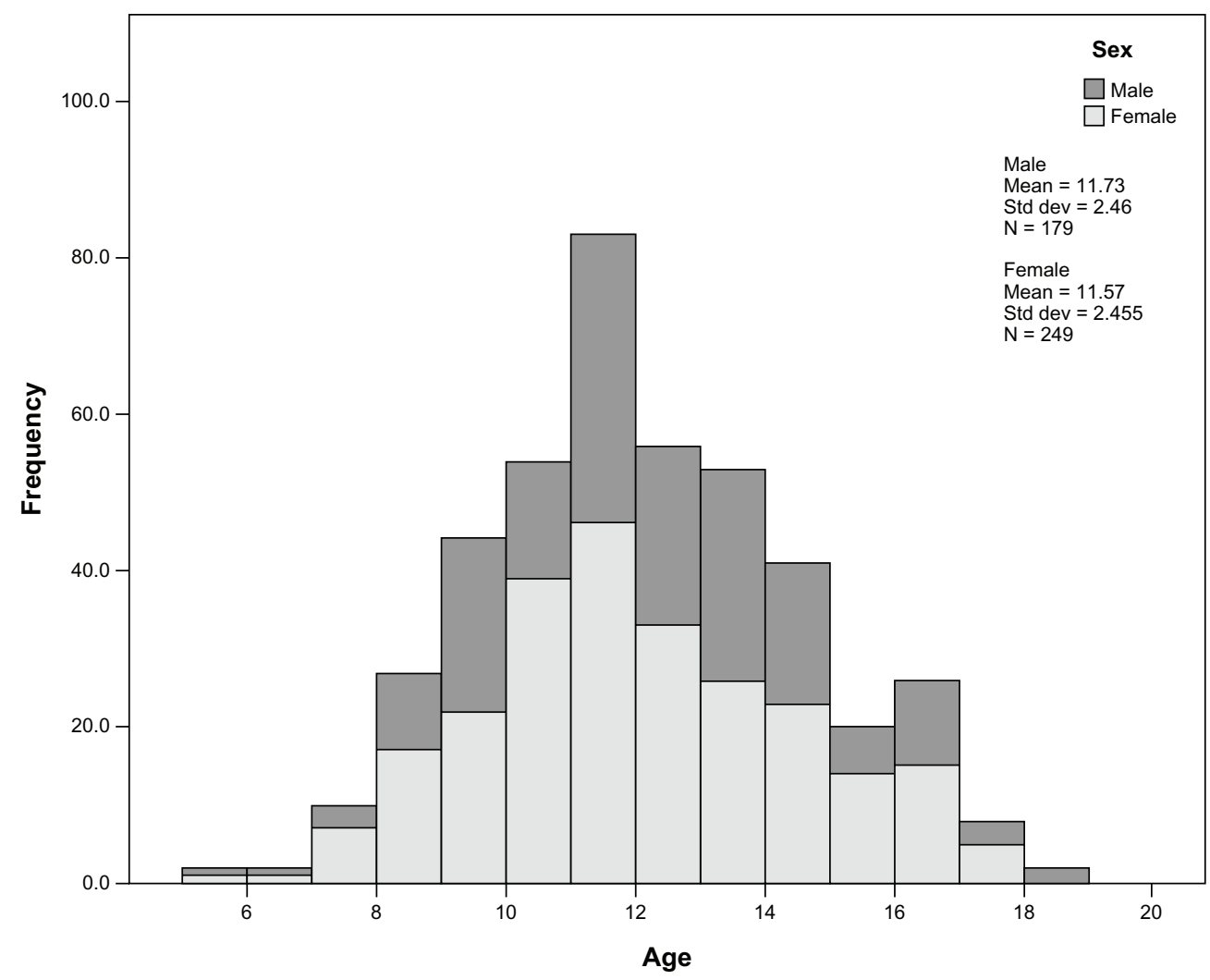

Figure I Age and sex distribution of the sample.

M3 development for females was stronger (Spearman's rho $=0.335)$ at a significance level of 0.01 .

The distribution of the different numbers of M3s detected in the sample was examined in both sexes and is described in Table 2. The presence of all four M3s was the most common incidence (present in $70.8 \%$ of patients), followed by the agenesis of two M3s (12.1\%), all M3s (8.4\%), one M3 (6.8\%), and three M3s (1.9\%). In females, four M3s were present in $42.3 \%$, the agenesis of two M3s in 7.2\%, all four M3s in 4.9\%, one M3 in $2.6 \%$, and three $\mathrm{M} 3 \mathrm{~s}$ in $1.2 \%$. In males, four M3s were present in $28.5 \%$, the agenesis of two in $4.9 \%$, all M3s in $3.5 \%$, one M3 in $4.2 \%$, and three $\mathrm{M} 3 \mathrm{~s}$ in $0.7 \%$. The agenesis of M3s occurred more frequently in females than in males, but the difference was not significant (Mann-Whitney $U$ test $=21,561.50, p=0.475$ ).

Table 3 summarizes the frequency of M3 agenesis in the maxilla and the mandible, and on the left and the right side. Congenitally missing M3s showed a greater predilection for the upper jaw (19.6\%) than the lower jaw (15.5\%), and an equal distribution between the right and left side of both jaws (approximately 17.5\%). The difference between the absent frequencies of M3s in the mandible and the maxilla was statistically significant for the total sample (McNemar test, $p=0$ ) and for males as well $(p=0.041)$. The maxillary predominance in the agenesis of M3s was not found statistically significant in females $(p=0.05)$. The differences between the two sides were not statistically significant for males or females.

Table 4 shows the percentages of patients with no, one, or both M3s present in the maxilla or the mandible, and on the right or the left side. In most cases, either both M3s were present in the maxilla or the mandible, or none was present. A total of $334(78.1 \%)$ patients had both M3s present in the maxilla, while $74(17.3 \%)$ of the patients showed no signs of any upper M3. In the mandible, both M3s were found in 347 patients $(81.1 \%)$ and none in 52 patients $(12.1 \%)$. For the total sample, the differences between the number of patients with M3s present in the maxilla and the mandible were found statistically significant (Wilcoxon signed-rank test $\mathrm{Z}=-2.404, p=0.016$ ). No significant sex differences were recorded. With regard to the two sides, it was more common for either two M3s or one M3 to be present. No difference was noted between the two sides, as both showed an equal distribution. A comparison between sexes did not reveal significant difference.

\section{Discussion}

The present study based on panoramic radiographs was conducted to investigate M3 genesis in a sample of Greek orthodontic patients. 
Table I Presence of third molars (M3 teeth) according to age and sex

\begin{tabular}{|c|c|c|c|c|c|c|}
\hline \multirow[t]{2}{*}{ Age, years } & \multirow[t]{2}{*}{ Sex } & \multicolumn{4}{|c|}{ Presence of each of the four M3 teeth, $n$} & \multirow{2}{*}{$\begin{array}{l}\text { Total number } \\
\text { of M3 teeth } \\
\text { present at } \\
\text { each age }\end{array}$} \\
\hline & & 18 & 28 & 38 & 48 & \\
\hline \multirow[t]{3}{*}{$5+$} & Male & 0 & 0 & 0 & 0 & 0 \\
\hline & Female & 0 & 0 & 0 & 0 & 0 \\
\hline & Total & 0 & 0 & 0 & 0 & 0 \\
\hline \multirow[t]{3}{*}{$6+$} & Male & 0 & 0 & 0 & 0 & 0 \\
\hline & Female & 0 & 0 & 0 & 0 & 0 \\
\hline & Total & 0 & 0 & 0 & 0 & 0 \\
\hline \multirow[t]{3}{*}{$7+$} & Male & 0 & 0 & 0 & 0 & 0 \\
\hline & Female & $3(100 \%)$ & $2(100 \%)$ & $2(100 \%)$ & $3(100 \%)$ & 10 \\
\hline & Total & 3 & 2 & 2 & 3 & 10 \\
\hline \multirow[t]{3}{*}{$8+$} & Male & 7 (43.8\%) & 7 (43.8\%) & $8(42.1 \%)$ & 8 (44.4\%) & 30 \\
\hline & Female & $9(56.3 \%)$ & $9(56.3 \%)$ & II (57.9\%) & $10(55.6 \%)$ & 39 \\
\hline & Total & 16 & 16 & 19 & 18 & 69 \\
\hline \multirow[t]{3}{*}{$9+$} & Male & $16(53.3 \%)$ & 16 (55.2\%) & I 8 (50\%) & I8 (48.6\%) & 68 \\
\hline & Female & 14 (46.7\%) & 13 (44.8\%) & I 8 (50\%) & 19 (5I.4\%) & 64 \\
\hline & Total & 30 & 29 & 36 & 37 & 132 \\
\hline \multirow[t]{3}{*}{$10+$} & Male & 12 (28.6\%) & II (26.2\%) & I3 (27.1\%) & I4 (29.8\%) & 50 \\
\hline & Female & 30 (7I.4\%) & 31 (73.8\%) & 35 (72.9\%) & 33 (70.2\%) & 129 \\
\hline & Total & 42 & 42 & 48 & 47 & 179 \\
\hline \multirow[t]{3}{*}{$11+$} & Male & $3 \mathrm{I}(44.9 \%)$ & 32 (45.7\%) & $30(44.1 \%)$ & 30 (44.1\%) & 123 \\
\hline & Female & 38 (55.1\%) & 38 (54.3\%) & 38 (55.9\%) & 38 (55.9\%) & 152 \\
\hline & Total & 69 & 70 & 68 & 68 & 275 \\
\hline \multirow[t]{3}{*}{$12+$} & Male & 22 (42.3\%) & $20(40 \%)$ & 22 (43.1\%) & $2 \mathrm{I}(40.4 \%)$ & 85 \\
\hline & Female & $30(57.7 \%)$ & $30(60 \%)$ & $29(56.9 \%)$ & 31 (59.6\%) & 120 \\
\hline & Total & 52 & 50 & 51 & 52 & 205 \\
\hline \multirow{3}{*}{$13+$} & Male & 20 (44.4\%) & 20 (44.4\%) & $26(50 \%)$ & 24 (48\%) & 90 \\
\hline & Female & $25(55.6 \%)$ & 25 (55.6\%) & $26(50 \%)$ & $26(52 \%)$ & 102 \\
\hline & Total & 45 & 45 & 52 & 50 & 192 \\
\hline \multirow[t]{3}{*}{ 14+ } & Male & 15 (42.9\%) & 17 (45.9\%) & $16(43.2 \%)$ & 17 (47.2\%) & 65 \\
\hline & Female & $20(57.1 \%)$ & 20 (54.1\%) & $2 \mathrm{I}(56.8 \%)$ & $19(52.8 \%)$ & 80 \\
\hline & Total & 35 & 37 & 37 & 36 & 145 \\
\hline \multirow[t]{3}{*}{$15+$} & Male & 5 (26.3\%) & 5 (26.3\%) & $4(23.5 \%)$ & $5(27.8 \%)$ & 19 \\
\hline & Female & $14(73.7 \%)$ & 14 (73.7\%) & $13(76.5 \%)$ & $13(72.2 \%)$ & 54 \\
\hline & Total & 19 & 19 & 17 & 18 & 73 \\
\hline \multirow[t]{3}{*}{$16+$} & Male & 10 (4I.7\%) & II (44\%) & 10 (43.5\%) & 10 (4I.7\%) & 41 \\
\hline & Female & 14 (58.3\%) & 14 (56\%) & $13(56.5 \%)$ & 14 (58.3\%) & 55 \\
\hline & Total & 24 & 25 & 23 & 24 & 96 \\
\hline \multirow[t]{3}{*}{$17+$} & Male & 2 (28.6\%) & 2 (28.6\%) & $2(28.6 \%)$ & 2 (33.3\%) & 8 \\
\hline & Female & 5 (71.4\%) & 5 (71.4\%) & 5 (7I.4\%) & $4(66.7 \%)$ & 19 \\
\hline & Total & 7 & 7 & 7 & 6 & 27 \\
\hline \multirow[t]{3}{*}{ 18+ } & Male & $2(100 \%)$ & $2(100 \%)$ & $2(100 \%)$ & $2(100 \%)$ & 8 \\
\hline & Female & 0 & 0 & 0 & 0 & 0 \\
\hline & Total & 2 & 2 & 2 & 2 & 8 \\
\hline \multirow[t]{3}{*}{ Total } & Male & 142 (41.3\%) & 143 (4I.6\%) & $|5|(4 \mid .7 \%)$ & I5I (4I.8\%) & 587 \\
\hline & Female & 202 (58.7\%) & $20 \mathrm{I}(58.4 \%)$ & 211 (58.3\%) & $210(58.2 \%)$ & 824 \\
\hline & Total & 344 & 344 & 362 & 361 & 14|| \\
\hline
\end{tabular}

Radiographic evidence of M3 formation has long been of concern to both dentists and orthodontists. The relationship of M3 formation with posterior crowding has been advocated for many years, and their agenesis, in addition to other permanent teeth, has been implicated in the degeneration of dentofacial development. ${ }^{2,7}$ Moreover, chronologic age estimation using the M3 commencement and end of mineralization has been used for a long time in forensic dentistry. ${ }^{3,4,13-18}$ Various classifications have been devised for evaluating tooth mineralization that differ from each other in terms of the number of stages and the definition of each stage..$^{2,4,5,19-23}$ Due to the use of different stage classifications and undetermined inter-observer error in some reports, processed data by different authors are not directly comparable. 
Table 2 Number of third molars (M3 teeth) per person and according to sex

\begin{tabular}{|c|c|c|c|c|c|c|c|}
\hline & \multicolumn{5}{|c|}{ Number of M3 teeth } & \multirow[t]{2}{*}{ Total } & \multirow[t]{2}{*}{$P$} \\
\hline & 0 & $\mathbf{I}$ & 2 & 3 & 4 & & \\
\hline \multicolumn{8}{|l|}{ Sex } \\
\hline \multicolumn{8}{|l|}{ Male } \\
\hline $\mathrm{N}$ & 15 & 3 & 21 & 18 & 122 & 179 & \\
\hline$\%$ of total & $3.5 \%$ & $0.7 \%$ & $4.9 \%$ & $4.2 \%$ & $28.5 \%$ & $41.8 \%$ & 0.260 \\
\hline \multicolumn{8}{|l|}{ Female } \\
\hline $\mathrm{N}$ & 21 & 5 & 31 & 11 & $|8|$ & 249 & \\
\hline$\%$ of total & $4.9 \%$ & $1.2 \%$ & $7.2 \%$ & $2.6 \%$ & $42.3 \%$ & $58.2 \%$ & \\
\hline \multicolumn{8}{|l|}{ Total } \\
\hline $\mathrm{N}$ & 36 & 8 & 52 & 29 & 303 & 428 & \\
\hline$\%$ of total & $8.4 \%$ & $1.9 \%$ & $12.1 \%$ & $6.8 \%$ & $70.8 \%$ & $100.0 \%$ & \\
\hline
\end{tabular}

Hence, in this study, we only investigated the onset of M3 formation, which was diagnosed radiologically either by the presence of uncalcified crypt or by the mineralization of cusp tips. The median ages of these events vary considerably among different populations and ethnicities. In a study concerning children from London, who were white and Bangladeshi, and Cape Town, who were Cape Coloured, it was reported that the mean age of initiation and almost all subsequent formation stages of permanent mandibular M3s were significantly delayed (at 9.06 years) compared with the black South African children (at 7.16 years). ${ }^{24}$ Accordingly, other studies of black people indicate that blacks achieve the formation stage significantly ahead of whites. ${ }^{4,25,26}$

In our sample, M3 tooth formation was detected during the seventh year (Table 1) and similar results were obtained for Turkish ${ }^{27,28}$ and Japanese children ${ }^{29}$ and for black children from South Africa. ${ }^{24}$ Spanish $^{6}$ and Croatian ${ }^{15}$ children have been reported to have earlier commencement of $\mathrm{M} 3$ formation (during and after the sixth year), while data recorded for other

Table 3 Number of maxillary, mandibular, right-, and left-side third molar (M3 teeth)

\begin{tabular}{|c|c|c|c|c|}
\hline \multirow[t]{2}{*}{ M3 teeth } & \multicolumn{2}{|l|}{ Sex } & \multirow[t]{2}{*}{ Total } & \multirow[t]{2}{*}{$P$} \\
\hline & Male & Female & & \\
\hline \multicolumn{5}{|c|}{ Maxillary $(18,28)$} \\
\hline Absent & 73 (8.5\%) & 95 (II.1\%) & $168(19.6 \%)$ & 0.663 \\
\hline Present & $285(33.3 \%)$ & $403(47.1 \%)$ & $688(80.4 \%)$ & \\
\hline \multicolumn{5}{|c|}{ Mandibular $(38,48)$} \\
\hline Absent & $56(6.5 \%)$ & 77 (9.0\%) & $133(15.5 \%)$ & 1.000 \\
\hline Present & $302(25.3 \%)$ & 42 I (49.2\%) & $723(84.5 \%)$ & \\
\hline \multicolumn{5}{|c|}{ Right side $(18,48)$} \\
\hline Absent & 65 (7.6\%) & $86(10 \%)$ & $151(17.6 \%)$ & 0.785 \\
\hline Present & $293(34.2 \%)$ & $4 I 2(48.1 \%)$ & 705 (82.4\%) & \\
\hline \multicolumn{5}{|c|}{ Left side $(28,38)$} \\
\hline Absent & $64(7.5 \%)$ & $86(10 \%)$ & $150(17.5 \%)$ & 0.856 \\
\hline Present & 294 (34.3\%) & 412 (48.1\%) & 706 (82.5\%) & \\
\hline
\end{tabular}

populations have reported a later onset of M3 development, ranging from 8 to 11 years. ${ }^{18,24,25,30-32}$

Banks $^{33}$ noted that crypts appeared between 5 and 14 years of age and the calcification of the maxillary M3 (18 and 28) was generally earlier than that of the mandibular one (38 and 48), the difference being from 1 to 2 years. Martin-de las Heras et $\mathrm{al}^{16}$ also reported a trend for M3 development to be more advanced in the maxilla than in the mandible. However, many other investigators have argued that the first appearance of M3 buds occurs in the mandible. 6,23,26,28,29,32 These findings may be related to the very poor visualization of the maxillary M3, at least until its entire occlusal surface is calcified, which means that maxillary M3s are difficult to identify at the initial stages of their development. In addition, it appears to be related to technological limitations, specifically to the superposition and distortion of anatomical structures in the orthopantomographs (OPGs) at the maxillary tuberosity level. ${ }^{6}$ In this study, there were no statistically significant differences between the upper and lower jaws with regard to the ages at which the initial stages of M3 mineralization were attained. This finding is in accordance with data recorded for black African, ${ }^{26}$ German, ${ }^{34}$ Turkish, ${ }^{27}$ and Chinese ${ }^{35}$ populations.

In our study, the first radiographic evidence of tooth formation was detected in female patients (Table 1), whereas males followed one year later. Female advance was also recorded in Japanese ${ }^{36}$ and South African populations, ${ }^{24}$ but this has not been a consistent finding. Most studies have reported either slight or no sex differences, $4,6,9,15,32,34,37$ or mean age earlier in boys compared with girls for all or

Table 4 Number of patients with varying degrees of absent third molars (M3 teeth) in the maxilla and the mandible, and on the right and the left side

\begin{tabular}{lllll}
\hline M3 teeth) & Sex & \multicolumn{1}{l}{ Total } & $P$ \\
\cline { 2 - 3 } & Male & Female & & \\
\cline { 1 - 3 } Maxillary & & & & \\
Both absent & $30(7.0 \%)$ & $44(10.3 \%)$ & $74(17.3 \%)$ & 0.096 \\
One absent & $13(3.0 \%)$ & $7(1.6 \%)$ & $20(4.6 \%)$ & \\
None absent & $136(31.8 \%)$ & $198(46.3 \%)$ & $334(78.1 \%)$ & \\
Mandibular & & & & \\
Both absent & $21(4.9 \%)$ & $31(7.2 \%)$ & $52(12.1 \%)$ & 0.772 \\
One absent & $14(3.3 \%)$ & $15(3.5 \%)$ & $29(6.8 \%)$ & \\
None absent & $144(33.6 \%)$ & $203(47.4 \%)$ & $347(81.1 \%)$ & \\
Right side & & & & \\
Both absent & $18(4.2 \%)$ & $25(5.8 \%)$ & $43(10.0 \%)$ & 0.880 \\
One absent & $29(6.8 \%)$ & $36(8.4 \%)$ & $65(15.2 \%)$ & \\
None absent & $132(30.8 \%)$ & $188(43.9 \%)$ & $320(74.8 \%)$ & \\
Left side & & & & \\
Both absent & $17(4.0 \%)$ & $24(5.6 \%)$ & $41(9.6 \%)$ & 0.919 \\
One absent & $30(7.0 \%)$ & $38(8.9 \%)$ & $68(15.9 \%)$ & \\
None absent & $132(30.8 \%)$ & $187(43.7 \%)$ & $319(74.5 \%)$ & \\
\hline
\end{tabular}


most stages of M3 development. ${ }^{9,14,31,36-38}$ This controversy supports further how unique and exceptional the M3 tooth is in the existence of sex and population differences worldwide, not only in terms of morphology but in terms of formation and calcification as well.

Concerning the relationship between age and M3 development, the present study has revealed a strong correlation between age and M3 development for both sexes. Specifically, females showed a stronger correlation (Spearman's rho $=0.335$ ) at a significance level of 0.01 than males (Spearman's rho $=0.177$ ) at a significance level of 0.05 . In contrast, Bolaños et $\mathrm{al}^{6}$ reported that this relationship is weak and very variable. However, our results are in agreement with most authors, who support a high correlation between M3 development and chronological age. 15,27,32,35

Delayed tooth formation has been noted with agenesis of one or more teeth, ${ }^{30,39}$ and it seems possible that a high level of agenesis in a population might be related to delayed M3 formation. In the present study, to avoid errors in the diagnosis, we also used panoramic radiographs taken during or after orthodontic treatment. Our results showed that in our sample $(\mathrm{n}=428)$ the number of M3s found was 1411 (Table 1). Therefore, $17.6 \%$ of M3s were congenitally missing. Similar results were obtained by Celikoglu et al ${ }^{1}$ with regard to a Turkish population $(17.3 \%$ congenitally missing M3s), which may indicate a similar trend of M3 agenesis between the two neighboring countries.

In the present study, it was also observed that most patients (70.8\%) had all four M3s, while the rest $(29.2 \%)$ had at least one M3 congenitally missing (Table 2). Observations made on a Jordanian population and a Chinese population resulted in similar findings, despite the differences between the age range of their samples (18.2 to 23.5 years and 12 to 16 years, respectively) and ours. Hattab et $\mathrm{al}^{40}$ reported that approximately $72.8 \%$ of Jordanian students were found with all four M3s and varying degrees of M3 agenesis were noted in the remaining $27.2 \%$ of their subjects. Mok and Ho's ${ }^{41}$ results were even closer to our findings, with the figures for their Chinese population being $71.5 \%$ and $28.5 \%$, respectively. Two other surveys closer to our age range on Spanish children ${ }^{6}$ aged between 4 and 20 years and Mexican children $^{31}$ aged between 7 and 18 years, conflict our data, reporting lower percentages (38\% of subjects with all four M3s present and $62 \%$ with at least one missing in the Spanish study, and $67.6 \%$ of subjects with all four M3s present and $32.4 \%$ with at least one absent M3 in the Mexican study). Other investigators who also studied the frequency of present M3s in different ethnic populations and at different age ranges
( $<15$ years, ${ }^{2}$ from 12 to 16 years, ${ }^{8}$ from 17.5 to 20 years $\left.{ }^{42}\right)$, have reported higher percentages of $\mathrm{M} 3$ presence ranging from $76 \%$ to $77 \%$. This diversity could be explained by the differences in the selected age range of the study populations. The absence of M3 formation is very frequent in series that include younger age groups, due to technical difficulties in the interpretation of OPGs for upper M3s. Being part of a larger survey, our former study ${ }^{3}$ on Greek patients with permanent dentition and a mean age of $13.62+1.81$ years showed that, out of the 220 patients, $20.9 \%$ had varying degrees of M3 agenesis. However, in the present study, we included younger ages in the sample, and the figure increased (29.2\%). It seems that regardless of efforts to avoid errors in the interpretation of radiographic evidence of M3s by examining OPGs taken at later chronological age, samples that include younger age groups may have a higher frequency of M3 agenesis that cannot be representative of the real epidemiology in the specific ethnic population. Thus, to avoid errors in the estimation of M3 agenesis, wider samples should be examined more closely radiologically from the early stages of life to adulthood.

The diversity could also be explained by the established ethnic differences. ${ }^{25}$ According to data, blacks are less likely to experience M3 hypodontia than whites. ${ }^{25}$ These results suggest the need for more studies worldwide to determine the genetic background of a specific population as well as its overall tendencies in terms of higher or lower frequencies of M3 agenesis.

Intersexual comparisons made in a Czech population with respect to the frequency of absent M3s showed that in males the most frequent agenesis was of one, followed by two, then three, and finally four M3s, while in females agenesis of two was most frequent, followed by one, and then equally of three and four M3s. ${ }^{43}$ However, our observations showed different frequencies of agenesis in both sexes. In males, it was most common for two M3s to be absent, followed by one, four, and three, while, in females, in most cases there was agenesis of two M3s, followed by four, one, and three M3s (Table 2). Different results were also obtained by Daito et al, who studied the agenesis of all four M3s in a Japanese population. ${ }^{29}$ According to their results, 9.5\% of males and $12 \%$ of females had no M3s. In contrast, in our study, the agenesis of all M3s was found to be significantly lower for both sexes (3.5\% for males and $4.9 \%$ for females) (Table 2).

The slight female predominance of M3 agenesis found in the present study agrees with results reported by many other investigators. ${ }^{1,29,31,42}$ Nevertheless, the intersexual 
comparisons in our sample have revealed non-statistically significant differences (Table 2), which is in agreement with the results reported for Chinese, ${ }^{41}$ Japanese, ${ }^{2}$ Turkish,${ }^{8}$ and Spanish $^{6}$ populations. In contrast, some studies have argued that there is greater sexual dimorphism in M3 agenesis and have reported results showing significant intersexual difference. For example, Daito et $\mathrm{al}^{29}$ reported a female predominance in $\mathrm{M} 3$ agenesis, while Rozkovcová et $\mathrm{al}^{43}$ and Liu et $\mathrm{al}^{44}$ reported that M3 agenesis was significantly more frequent in males than in females. A greater male-female difference has also been reported in whites compared with blacks. ${ }^{14,25}$ In blacks, the frequencies of agenesis were not statistically different, but in whites a statistical difference was found, with white females being 1.8 times more likely to have a missing mandibular M3 than males. ${ }^{45}$

Our findings concerning the frequency of M3 agenesis in the maxilla and the mandible showed that the proportion of M3 agenesis in the maxilla was significantly higher (19.6\% [168 teeth of a total of 856]) than that in the mandible (15.5\% [133/856]), with no significant sex differences (Table 3). In a Jordanian population, congenitally missing M3s showed a predilection for the mandible over the maxilla. ${ }^{40}$ However, our results on the maxillary predominance of $\mathrm{M} 3$ agenesis are in accordance with data reported by other researchers for other ethnic populations. ${ }^{8,41,42,46}$ In Asian-Indian ${ }^{42}$ and Chinese $^{41}$ populations, significantly more M3 teeth were found to be missing from the maxilla compared to the mandible, at a ratio of approximately 3:2. The ratio for our sample was lower than that reported for the East Anatolian population but closer to that reported for the Turkish population (approximately 1.5:1.0). ${ }^{8}$

The incidence of M3 agenesis was found to be equal for both sides (Table 3). This is in agreement with other authors who have reported no significant differences in M3 agenesis between the right and left sides. ${ }^{8,40,41,44}$ Further, our results showed that there was no sexual dimorphism in the number of absent M3s between the two sides (McNemar test, $p=1$ ) (Table 3). These data may indicate a genetic trend for no side predilection in M3 agenesis in both males and females.

According to data shown in Table 4, congenitally missing M3s in all subjects showed a significantly greater predilection for the maxilla over the mandible (Wilcoxon signed-rank test $Z=-2.404, p=0.016$ ). The number of subjects that had both upper M3s congenitally missing was $74(17.3 \%)$, whereas $52(12.1 \%)$ had bilateral agenesis of the lower M3s. However, intersexual differences were not statistically significant. Studies performed in different populations have also demonstrated a maxillary predominance of M3 agenesis..$^{8,27,40-42,46}$ Nevertheless, the diagnosis of agenesis of maxillary M3s must be made with caution because initial developmental stages are not always visible in the maxilla.

In our sample, bilateral agenesis of M3s in the mandible seemed less frequent in males than in females, the proportions being $4.9 \%$ and $7.2 \%$, respectively $(12.1 \%$ of the total sample) but these values were not statistically different (Table 4). In contrast, in a French Canadian population, a male predominance over females was found for bilateral agenesis of mandibular M3s, the proportions being 11.1\% and $7.1 \%$, respectively ( $9 \%$ in the total sample). ${ }^{9}$ Moreover, the percentages of subjects with at least one absent M3 in either the maxilla or the mandible were found to be $21.9 \%$ and $18.9 \%$, respectively (Table 4). According to results reported by other investigators, the percentage of Japanese children with at least one missing M3 in the maxilla was $17 \%$ while the percentage with at least one missing $\mathrm{M} 3$ in the mandible was $11.4 \% .^{2}$ At least one maxillary M3 was found absent from $5 \%$ of black and $8.9 \%$ of white Americans, ${ }^{25}$ while the figures for the mandible were $2.7 \%$ and $11.2 \%$, respectively. A female predilection for M3 agenesis was also shown in white Americans, with females being 1.8 times more likely to have a missing mandibular M3 than males. ${ }^{14}$ These deviations raise the interesting issue of population and ethnic differences in the absence of M3 tooth formation. Not only are there broad ethnic differences in the incidence of M3 congenital agenesis, but the data show that M3 agenesis among groups is not the same.

Finally, for the total sample, and according to sex, the number of subjects with absent M3s was found almost equal for both sides (Table 4). This result was similar to other researchers' results obtained from studies in other ethnic populations worldwide, and may be indicative of a genetic trend for no special predilection in M3 agenesis regarding the left and the right sides in either maxilla or mandible. ., $, 40,41,44^{2}$

\section{Conclusion}

Radiological evidence of M3 genesis has been reported to occur over a wide age range in different populations worldwide. In this specific study group from northern Greece, it was observed that the earliest age at which M3s were radiographically evident was 7 years old. Although most studies have reported either slight or no demonstrable sex difference in M3 formation and calcification, or male advance with regard to these events compared with females, in this study, M3 formation was attained earlier in 
females ( 7 years) than in males, who followed one year later ( 8 years). Therefore, more studies may be needed to clarify this and further investigation of the chronological age of M3 formation is required to determine and decipher the real difference among different geographic groups to attain a more accurate estimation of chronological age.

The M3 was absent in $29.2 \%$ of the Greek orthodontic patients, with a slight predominance of females over males. The order of frequency of absent M3s was two, followed by four, one, and three M3s. Congenitally missing teeth accounted for $17.6 \%$ and showed a greater predilection for the maxilla than the mandible, but the distribution of absent M3s was found equal between the right and left side of both jaws.

The data described above may provide a reference for M3 development in examinations of the Greek population. However, the wide individual variability in the formation of M3 teeth may suggest that additional studies with larger study populations should be conducted to meet the need for population-based information on M3 development and enrich the pool of existing data.

\section{Disclosure}

The authors declare no conflicts of interest in this work.

\section{References}

1. Celikoglu M, Miloglu O, Kazanci F. Frequency of agenesis, impaction, angulation, and related pathologic changes of third molar teeth in orthodontic patients. J Oral Maxillofac Surg. 2010;68(5):990-995.

2. Kajii T, Imai T, Kajii S, Iida J. Presence of third molar germs in orthodontic patients in Japan. Am J Orthod Dentofacial Orthop. 2001; 119(3):245-250.

3. Saysel MY, Meral GD, Kocadereli I, Taşar F. The effects of first premolar extractions on third molar angulations. Angle Orthod. 2005; 75(5):719-722.

4. Gorgani N, Sullivan RE, DuBois L. A radiographic investigation of third-molar development. ASDC J Dent Child. 1990;57(2):106-110.

5. Barnett DP. Late development of a lower third molar-a case report. $\mathrm{Br}$ J Orthod. 1976;3(2):111-112.

6. Bolaños MV, Moussa H, Manrique MC, Bolaños MJ. Radiographic evaluation of third molar development in Spanish children and young people. Forensic Sci Int. 2003;133(3):212-229.

7. Richardson M. Late third molar genesis: its significance in orthodontic treatment. Angle Orthod. 1980;50(2):121-128.

8. Kazanci F, Celikoglu M, Miloglu O, Oktay H. Third-molar agenesis among patients from the East Anatolian Region of Turkey. J Contemp Dent Pract. 2010;11(4):E033-E040.

9. Levesque GY, Demirijian A, Tanguay R. Sexual dimorphism in the development, emergence, and agenesis of the mandibular third molar. J Dent Res. 1981;60(10):1735-1741.

10. Barka G, Tretiakov G, Theodosiou T, Ioannidou-Marathiotou I. Presence of third molars in orthodontic patients from northern Greece. Int J Gen Med. 2012;5:441-447.

11. Durkalski VL, Palesch YY, Lipsitz SR, Rust PF. Analysis of clustered matched-pair data. Stat Med. 2003;22(15):2417-2428.

12. Field A. Discovering Statistics Using SPSS for Windows, 3rd ed. London: Sage; 2009.
13. Friedrich RE, Ulbricht C, von Maydell LA, Scheuer HA. The impact of wisdom teeth topography on chronology of root formation - forensic consequence for forensic-odontologic age estimation of adolescents and young adults. Radiographic investigations using orthopantomography. Arch Kriminol. 2005;216(1-2):15-35. German.

14. Harris EF. Mineralization of the mandibular third molar: a study of American blacks and whites. Am J Phys Anthropol. 2007; 132(1): 98-109.

15. Legović M, Sasso A, Legović I, et al. The reliability of chronological age determination by means of mandibular third molar development in subjects in Croatia. J Forensic Sci. 2010;55(1):14-18.

16. Martin-de las Heras S, García-Fortea P, Ortega A, Zodocovich S, Valenzuela A. Third molar development according to chronological age populations from Spanish and Magrebian origin. Forensic Sci Int. 2008;174(1):47-53.

17. Mesotten K, Gunst K, Carbonez A, Willems G. Dental age estimation and third molars: a preliminary study. Forensic Sci Int. 2002; 129(2):110-115.

18. Sisman Y, Uysal T, Yagmur F, Ramoglu SI. Third-molar development in relation to chronologic age in Turkish children and young Adults. Angle Orthod. 2007;77(6):1040-1045.

19. Demirjian A. Dentition. In: Falkner F, Tanner JM, editors. Human Growth. New York, NY: Academic Press; 1986:269-298.

20. Demirjian A, Goldstein H, Tanner JM. A new system of dental age assessment. Hum Biol. 1973;45(2):221-227.

21. Hagg U, Matsson L. Dental maturity as an indicator of chronological age: the accuracy and precision of three methods. Eur J Orthod. 1985; $7(1): 25-34$.

22. Olze A, Pynn BR, Kraul V, et al. Studies on the chronology of third molar mineralization in First Nations people of Canada. Int $J$ Legal Med. 2010;124(5):433-437.

23. Willershausen B, Löffler N, Schulze R. Analysis of 1202 orthopantomograms to evaluate the potential of forensic age determination based on third molar developmental stages. Eur J Med Res. 2001;6(9):377-384.

24. Liversidge HM. Timing of human mandibular third molar formation. Ann Hum Biol. 2008;35(3):294-321.

25. Harris EF, Clark LL. Hypodontia: an epidemiologic study of American black and white people. Am J Orthod Dentofacial Orthop. 2008; 134(6):761-767.

26. Olze A, van Niekerk P, Schmidt S, et al. Studies on the progress of third molar mineralisation in a Black African population. Homo. 2006;57(3):209-217.

27. Orhan K, Ozer L, Orhan AI, Dogan S, Paksoy CS. Radiographic evaluation of third molar development in relation to chronological age among Turkish children and youth. Forensic Sci Int. 2007; 165(1):46-51.

28. Uzamis M, Kansu O, Taner TU, Alpar R. Radiographic evaluation of third-molar development in a group of Turkish children. ASDC J Dent Child. 2000;67(2):136-141.

29. Daito M, Tanaka T, Hieda T. Clinical observations on the development of third molars. J Osaka Dent Univ. 1992;26(2):91-104.

30. Garn SM, Lewis AB, Vicinus JH. Third molar agenesis and reduction in the number of other teeth. J Dent Res. 1962;41(3):717.

31. Nuño González MM, Llarena del Rosario ME. Radiographic study of formation and calcification of the third molar. Pract Odontol. 1990; 11(11):27-31. Spanish.

32. Sarnat H, Kaffe I, Porat J, Amir E. Developmental stages of the third molar in Israeli children. Pediatr Dent. 2003;25(4):373-377.

33. Banks HV. Incidence of third molar development. Angle Orthod. 1934; 4(3):223-233.

34. Olze A, Taniguchi M, Schmeling A, et al. Comparative study on the chronology of third molar mineralization in a Japanese and a German population. Legal Med (Tokyo). 2003;5 Suppl 1:S256-S260.

35. Zeng DL, Wu ZL, Cui MY. Chronological age estimation of third molar mineralization of Han in southern China. Int J Legal Med. 2010; 124(2):119-123. 
36. Olze A, Taniguchi M, Schmeling A, et al. Studies on the chronology of third molar mineralization in a Japanese population. Legal Med (Tokyo). 2004;6(2):73-79.

37. Anderson DL, Thompson GW, Popovich F. Age of attainment of mineralization stages of the permanent dentition. J Forensic Sci. 1976; 21(1):191-200.

38. Moorrees CF, Fanning EA, Hunt EE Jr. Age variation of formation stages for ten permanent teeth. J Dent Res. 1963;42:1490-1502.

39. Uslenghi S, Liversidge HM, Wong FSL. A radiographic study of tooth development in hypodontia. Arch Oral Biol. 2006;51(2):129-133.

40. Hattab FN, Rawashdeh MA, Fahmy MS. Impaction status of third molars in Jordanian students. Oral Surg Oral Med Oral Pathol Oral Radiol Endod. 1995;79(1):24-29.

41. Mok YY, Ho KK. Congenitally absent third molars in 12 to 16 year old Singaporean Chinese patients: a retrospective radiographic study. Ann Acad Med Singapore. 1996;25(6):828-830.
42. Sandhu S, Kaur T. Radiographic evaluation of the status of third molars in the Asian-Indian students. J Oral Maxillofac Surg. 2005; 63(5):640-645.

43. Rozkovcová E, Marková M, Láník J,Zvárová J. Development of third molar in the Czech population. Prague Med Rep. 2004;105(4):391-422.

44. Liu XQ, Sun XY, Chen J, Liu J, Xu H, Fan CH. A statistic analysis on absence of third molar germs in orthodontic patients. Hua Xi Kou Qiang Yi Xue Za Zhi. 2004;22(6):493-495. Chinese.

45. Harris EF, McKee JH. Tooth mineralization standards for blacks and whites from the middle southern United States. J Forensic Sci. 1990; 35(4):859-872.

46. Topkara A, Sari Z. Prevalence and distribution of hypodontia in a Turkish orthodontic patient population: results from a large academic cohort. Eur J Paediatr Dent. 2011;12(2):123-127.
International Journal of General Medicine

\section{Publish your work in this journal}

The International Journal of General Medicine is an international, peer-reviewed open-access journal that focuses on general and internal medicine, pathogenesis, epidemiology, diagnosis, monitoring and treatment protocols. The journal is characterized by the rapid reporting of reviews, original research and clinical studies across all disease areas.

\section{Dovepress}

A key focus is the elucidation of disease processes and management protocols resulting in improved outcomes for the patient.The manuscript management system is completely online and includes a very quick and fair peer-review system. Visit http://www.dovepress.com/ testimonials.php to read real quotes from published authors.

Submit your manuscript here: http://www.dovepress.com/international-journal-of-general-medicine-journal 